\title{
History and prospects of the application of $X$ - ray in seed production and seed studies
}

\author{
F B Musaev ${ }^{1}, N N$ Potrakhov $^{2}$, and $S L$ Beletskiy, \\ ${ }^{1}$ Federal Scientific Vegetable Center (FSBSI FSVC), Selectionnaya str., 14, VNIISSOK, Odintsovo \\ district, Moscow region, 143072, Russia \\ ${ }^{2}$ Saint Petersburg Electrotechnical University "LETI", Professora Popova str., 5, St. Petersburg, \\ 097022, Russia \\ ${ }^{3}$ Scientific Research Institute of Storage Problems Federal Agency of State Reserves, Volochaevskaya \\ str., 40/1, Moscow, 111033, Russia
}

\begin{abstract}
A retrospective analysis of the history of the application of the method of radiography in the course of studies of the structure of seeds for the purposes of seed production and seed studies was carried out. It is shown that the beginning of X-ray studies of seeds is directly related to the development in the late 70 s of the last century in the Special Design Bureau for X-ray Instruments, Leningrad Association of Electronic Instrumentation "Svetlana" of a specialized X-ray apparatus based on the $\mathrm{X}$-ray emitter REIS with a voltage of $25 \mathrm{kV}$. The methodological part of the research was provided by the leading specialized enterprises of our country, now they are FSBSI API, FSBI Research Institute for Storage Problems of the Federal Reserve FSBSI FSVC. In the early 2000s, ETU "LETI", represented by a small enterprise of the Technopark LETI, CJSC "ELTECH-Med", actively joined the research. LETI is associated with the transition to digital receivers of X-ray images, which made it possible to fundamentally increase the efficiency of research by employees of CJSC "ELTECH-Med" together with specialists from Agrophysical Research Institute, FSBI Research Institute for Storage Problems of the Federal Reserve, FSBSI FSVC developed a number of technical means for obtaining digital 2 and 3 dimensional X-ray images of seeds.
\end{abstract}

\section{Introduction}

The method of X-ray diffraction of various objects in order to visualize their interna 1 structure has been known for more than a hundred years - since the discovery of X-ray radiation by V.K. Roentgen in 1895 . The method still remains in demand in almost all branches of human activity and continues to actively develop. The seeds of agricultural crops were one of the first objects of diagnosis by this method. However, at that time, radiographic studies of seeds in agronomy did not receive systemic development. The reason is the small size of the seeds, which did not allow, at the current level of

\footnotetext{
* Corresponding author: grain-miller@yandex.ru
} 
development of technical means of radiography, extracting the necessary amount of information about the internal structure of the seed.

\section{Materials and methods}

In this regard, studies on the use of X-rays in seed production has developed slowly. The first serious work on X-ray diffraction of plant objects began abroad on the seeds of tree species [1-2]. Gradually, similar works have become widespread in our country [3-6]. In 1988, the USSR State.

Subsequently, a wide range of studies was carried out on the X-ray assessment of the quality of collection samples of seeds from the world collection of the All-Russian Institute of Plant Genetic Resources. The quality of seeds before storage and the dynamics of its change during storage were Forestry Committee approved the industry standard "Seeds of tree species. X-ray analysis methods" (OST 56-94-88). analyzed with the possibility of recording the results of analysis [8-10].

However, in general, studies in the field of seed quality control by studying their internal structure developed at a low rate due to the lack of appropriate technical means. Seeds were surveyed in the classical way - on X-ray film using X-ray machines with an extended focal spot. The seeds had to be placed as close to the image receiver as possible to prevent geometric blurring of the image. As a result, the images were obtained without projection magnification and had little information content. In addition, the "film" technology for imaging X-ray images was time-consuming and labor-intensive. Therefore, classical radiography did not allow solving the problem in full.

The development of microfocus X-ray sources and specialized X-ray devices based on them, as well as the appearance of digital X-ray image detectors, gave a new impetus to research.

One of the first X-ray machines designed to take pictures of seeds of agricultural plants in order to determine their sowing qualities was the ELECTRONICA-25 apparatus (Fig. 1).

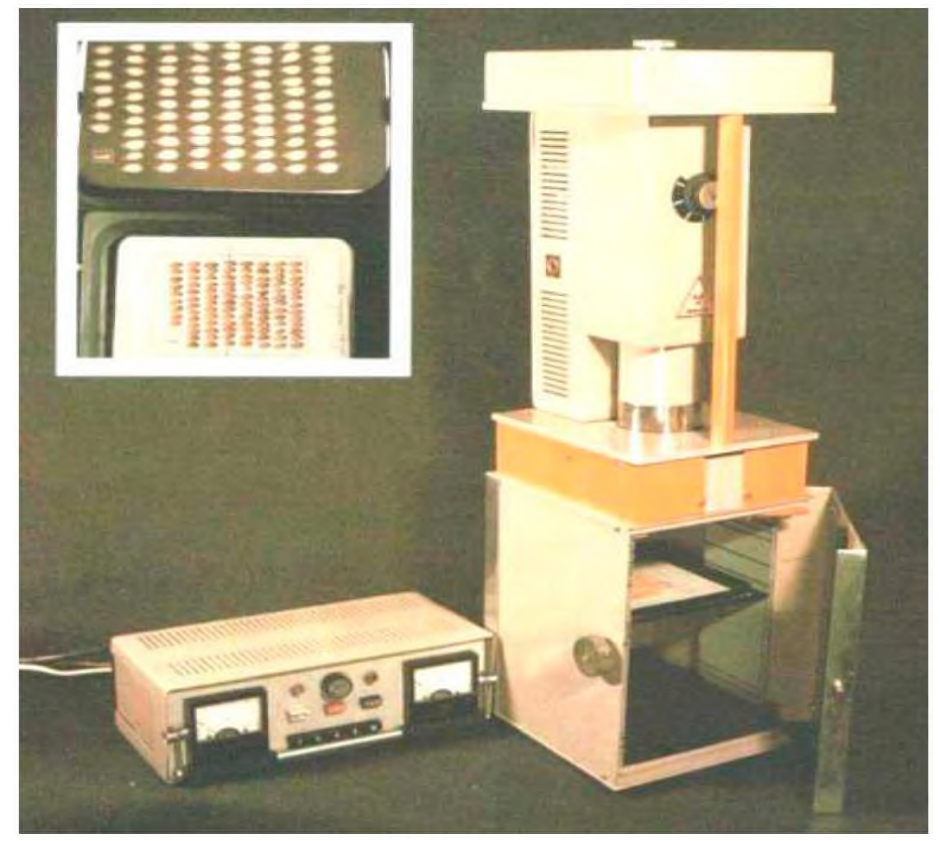

Fig. 1. ELECTRONICS-25 X-ray apparatus. 
The device made it possible to obtain images of individual seeds with an image magnification up to 10 times. It included a microfocus X-ray source of the REIS family, as well as a small-sized camera for performing X-ray work [11]. The REIS X-ray source was designed on the basis of the first domestic X-ray tube with a hollow remote anode and a target of the BS series. The design of this tube, developed at the Special Design Bureau for X-ray Instruments, Leningrad Association of Electronic Instrumentation "Svetlana" (Leningrad) and for decades determined the main direction of development of microfocus X-ray sources in our country, can be considered classical [12].

In the late $80 \mathrm{~s}$, a portable microfocus X-ray emitter of the REIS family for $100 \mathrm{kV}$ was created. The use of this emitter for X-ray diffraction of agricultural seeds made it possible to carry out work on assessing the economic suitability of not only seeds, but also various plants [13-14].

\section{Results}

Since the beginning of the introduction of microfocus X-ray sources into the X-ray diffraction of plant objects, extensive research has begun to study the internal structure of agricultural seeds in order to improve their quality. The leading institution in this area of seed production is the Scientific Research Institute of the API (now the Federal State Budgetary Scientific Institution "Agrophysical Research Institute"). In the laboratory of seed biophysics of this institute, the X-ray method was first adapted specifically for seeds of agricultural plants and is currently used to study a wide range of seeds of cereals, legumes, oilseeds and forage grasses [15-17], [18-22]. Over time, the St. Petersburg State Electrotechnical University "LETI" named after V.I. Ulyanov (Lenin) and All-Russian Research Institute of Selection and Seed Production of Vegetable Crops (VNIISSOK) (now FSBSI Federal Scientific Vegetable Center) joined these studies. At the same time, the members of the Department of Electronic Devices of SPb SEU "LETI" focused on research in the field of creating promising technical means of seed X-ray. So, in the development of the design of the ELECTRONICA-25 apparatus, together with ELTECH-Med CJSC (Technopark of St. Petersburg State Electrotechnical University "LETI"), the development of X-ray diagnostic units of the PRDU family was started [23].

Currently, a whole family of PRDU mobile X-ray diagnostic units has been created, designed for the study of large plants, including tree species, as well as whole batches of vegetable seeds, grain, etc. cultures in a specialized laboratory. The devices allow obtaining, depending on the problem being solved, an X-ray image of an individual grain with a magnification factor of 10 times or more.

In addition to a microfocus X-ray source and a digital image receiver, the unit of a PRDU family includes a specialized camera for performing X-ray work (Fig. 2). 


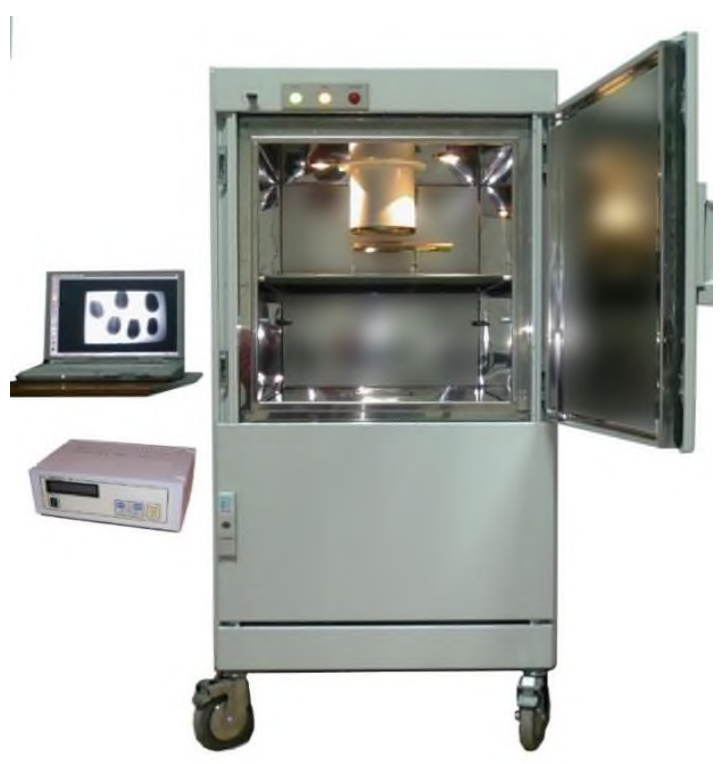

Fig. 2. PRDU-02 mobile $X$-ray diagnostic.

In the course of developing the design of the unit, the capabilities of two types of digital $\mathrm{X}$-ray image detectors for the purpose of X-ray imaging of seeds were assessed: based on the screen-optics-CCD-matrix system, and also on the basis of a screen with a photostimulated luminophore (PSL). It was found that receivers based on a PSL screen are more sensitive and provide a higher quality of the X-ray image due to the higher resolution. However, the cost of an imaging system based on a PSL screen is several times higher than that of a screen-optics-CCD-matrix system.

A portable hardware-software complex designed for examining small-sized plant fragments or individual seeds directly in a field, forest, etc. has become a fundamentally new technical means of X-ray imaging. For this purpose, the first domestic microfocus apparatus with a built-in rechargeable power source of the PARDUS family was included in the complex (Figure 3). The low power of the apparatus in combination with the high sensitivity of the digital receiver of the X-ray image makes it possible to provide radiationsafe working conditions for the operator during X-ray examinations.

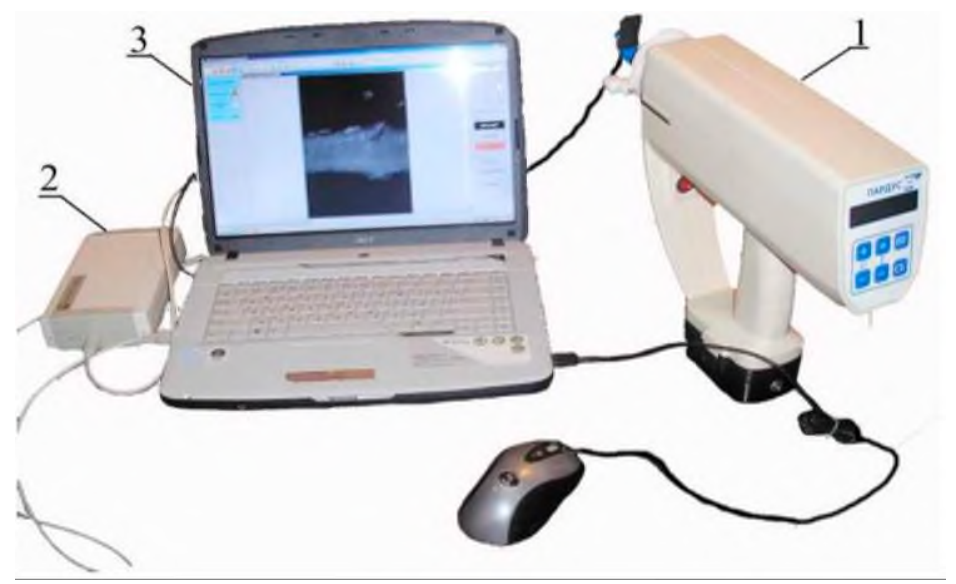

Fig. 3. Portable X-ray diagnostic complex of the PARDUS family. 
All the described technical means of X-ray of seeds make it possible to visualize the main types of their defects: incompleteness, embryo defects, fractures, hidden damage by insects, damage by fungal and bacterial infections, hidden germination of seeds.

To study the "smaller" morphological features of the structure of seeds, it is necessary to obtain their image with a high magnification. For this purpose, another specialized unit was developed - an X-ray microscope RM-01 (Fig. 4).

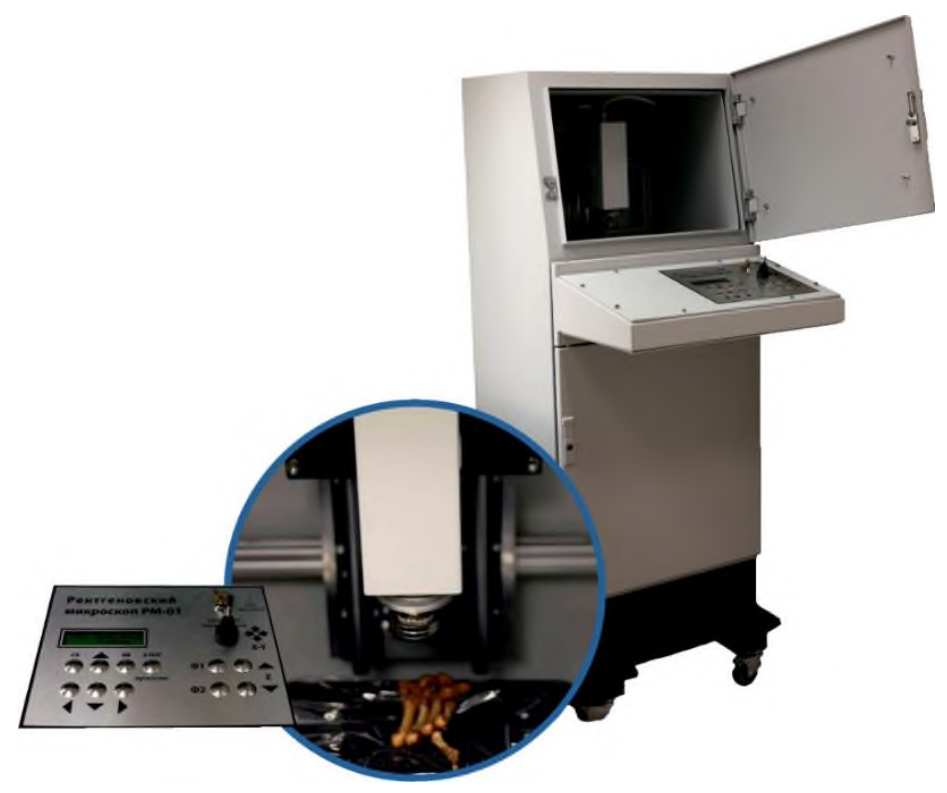

Fig. 4. X-ray microscope RM-01.

Unlike units of the PRDU family, the RM-01 unit allows obtaining images of individual seeds with an increase of up to several hundred times. For this purpose, the object of photography is placed in a special holder, which in automatic mode ensures the movement of the object in the horizontal and vertical planes, as well as rotation around the axis. In the basic version of the RM-01 unit, the X-ray image is visualized using an image receiver built according to the "screen - optics - CCD" scheme [23-24]. However, it is possible to use more modern X-ray image detectors, for example, based on large-format solid-state X-ray detectors.

During this period, foreign scientists also advanced in research on seed radiography. Different works in the field of comprehensive analysis of the quality of grain of cereals and seeds of industrial crops were developed [25-28]. The method of X-ray diffraction of seeds also began to be used to solve various problems of biology and seed science [29-30]. By means of X-ray analysis of the internal structure of pepper seeds [31], conclusions about their viability are made. The intervals between the endosperm and the embryo on X-ray images of seeds are used to judge their ripeness and moisture content, and to determine the quality of future seedlings [32].

In recent years, the FSBSI Federal Scientific Vegetable Center has carried out largescale studies on the radiography of vegetable seeds. Together with the members of the FSBSI API and St. Petersburg State Electrotechnical University "LETI", the main defects and shortcomings of the internal structure of vegetable seeds, which have economic and biological significance and affect their quality, have been identified and classified. The studies were systematized for 26 species of vegetable crops belonging to 11 botanical families [33-34]. Examples of digital X-ray images of vegetable seeds are shown in Fig. 5. 


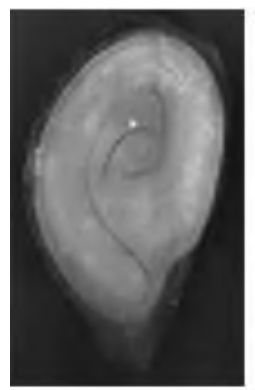

a

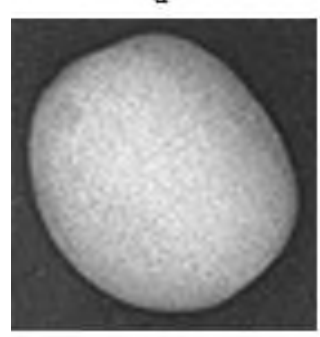

e

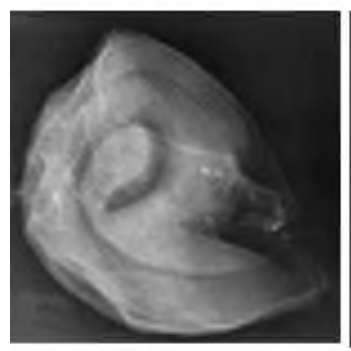

j

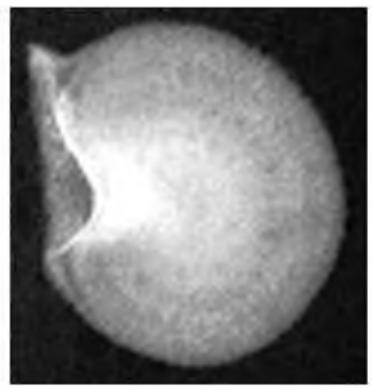

b

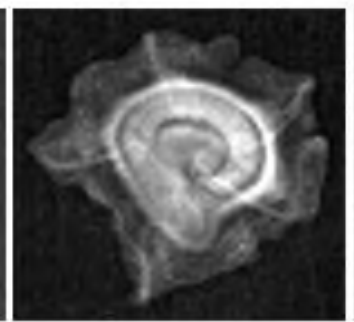

f

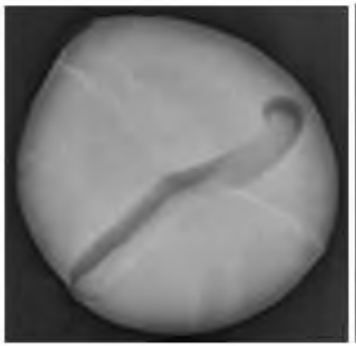

$\mathrm{k}$

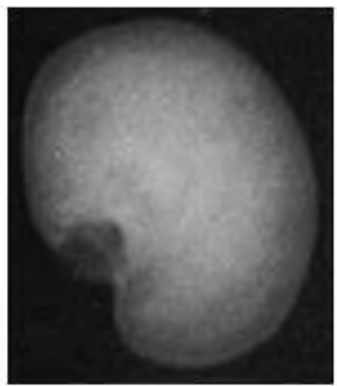

c

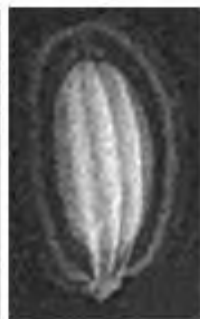

$\mathrm{g}$

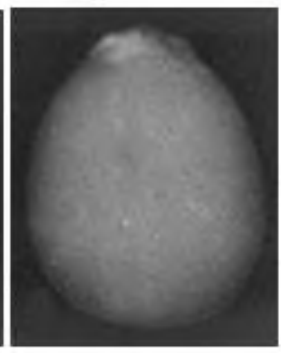

1

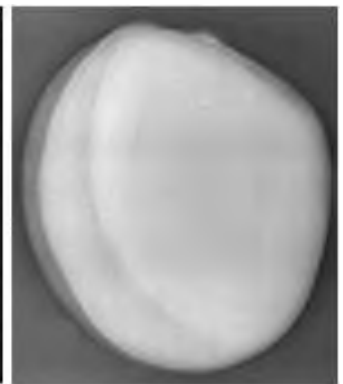

d

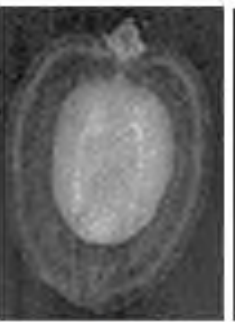

h

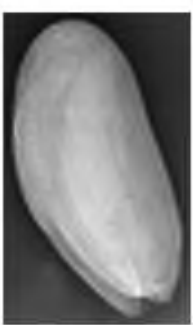

i

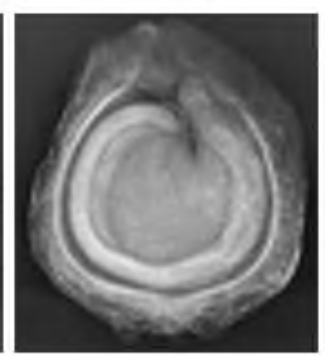

$\mathrm{m}$

Fig. 5. X-ray image of seeds of various vegetable crops: $a$ - tomato; $b$ - pepper; $c$ - eggplant; $d-$ radish; $e$ - cabbage; $f$ - beet; $g$ - dill; $h$ - parsnip; $i$ - garden cress; $j$ - onion; $k$ - asparagus; $l$ marjoram; $m$ - spinach.

For more than 10 years, the main area in the development of seed X-ray diffraction has been the development of algorithms for the automated analysis of their quality. Employees of ETU "LETI", FSBSI API, FSBSI "FSVC", and FSBI Research Institute for Storage Problems of the Federal Reserve work in this area for grain and vegetables. An algorithm for computer analysis of seed quality has been developed, consisting of the following stages: preparation of X-ray images for analysis, including compensation for distortions caused by the geometry of the survey and the presence of artifacts, identification of objects in the X-ray image, identification of seed defects, fractional analysis, automatic preparation of the analysis protocol.

The algorithm is implemented in a hardware and software complex developed at ELTECH-Med CJSC. Together with the FSBI Research Institute for Storage Problems of the Federal Reserve, a software and hardware complex based on an X-ray unit of the PRDU family was developed and successfully tested (Fig. 6). 


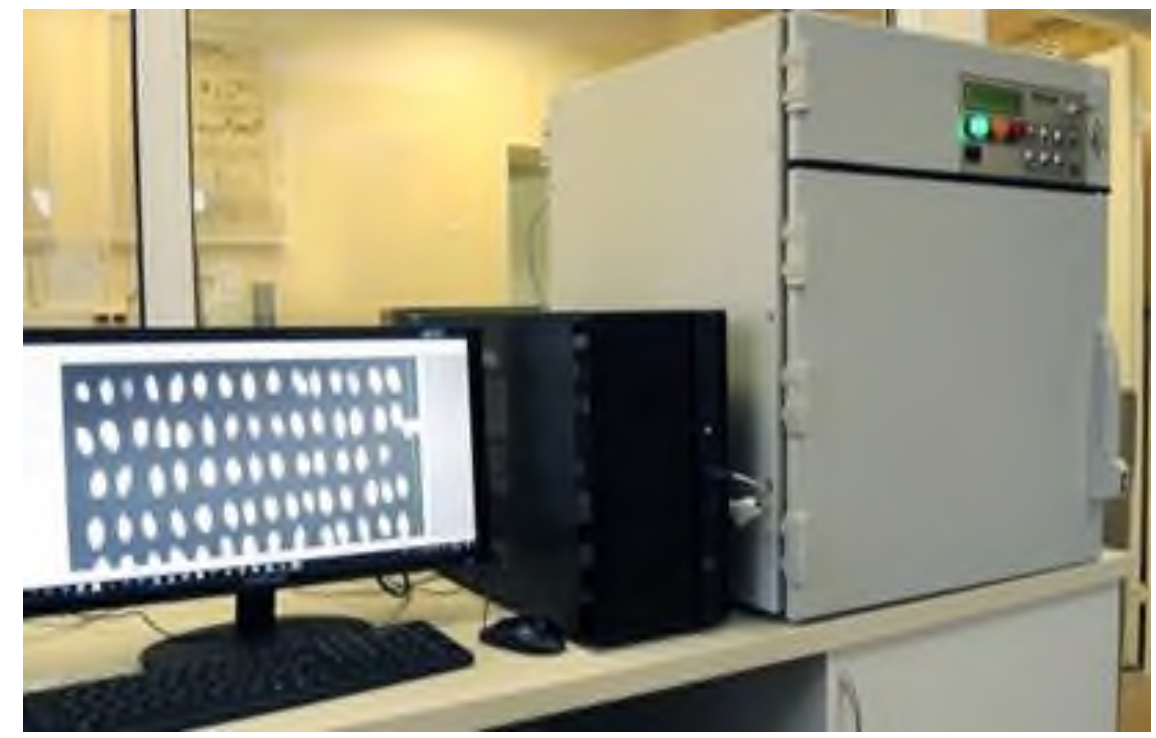

Fig. 6. Hardware and software complex based on an X-ray unit of the PRDU family.

The programs for automatic computer analysis of the quality of seeds "Agrotest-Zerno1", "Agrotest-Zerno-2", "SortSemControl-1.0", "Passport-grain" have been developed and tested $[38,39]$. Research continues, new versions of programs are being developed in order to increase their ability to recognize defects. The method for measuring internal defects of grain using an X-ray diagnostic installation of the PRDU-02 type was certified (Certificate of competence of the measurement method No. 241.0283/RA.RU.311866/2017).

One of the most modern and promising methods for obtaining high-resolution images, including three-dimensional ones, is X-ray computed tomography. The method developed in Germany for three-dimensional visualization of beet seeds (fruits) in flow mode [35] is currently the highest achievement in the field of seed radiography.

To solve similar problems, the members of the laboratory of X-ray television systems of ETU "LETI" together with ELTECH-Med CJSC developed a family of domestic microfocus X-ray computed tomographs - MRKT [36-37].

One of the latest developments - the MRKT-04 tomograph is shown in Fig. 7.

Its design is based on an X-ray protective chamber. The material and wall thickness of the chamber provide complete protection against unused X-ray radiation in accordance with current regulations. Inside the chamber, there are RAP-150M monoblock x-ray sources with a BS16 microfocus X-ray tube and X-ray sources based on a solid-state flat-panel twocoordinate detector.

Unlike units of the PRDU family (except for RM-01), tomographs are additionally equipped with an automated device for rotation and movement along the axis of the X-ray beam of the object of study. 


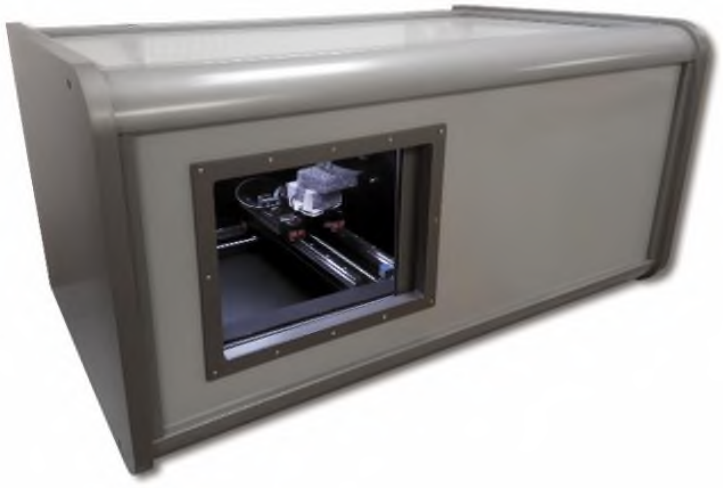

Fig. 7. Microfocus X-ray computed tomograph MRKT-04.

The original software is used to control the operation of the main units of the tomograph, collect and process projection data, as well as reconstruct a three-dimensional image of the research object.

The maximum voltage on the $\mathrm{X}$-ray tube of the tomograph is $150 \mathrm{kV}$, the maximum tube current is $0.1 \mathrm{~mA}$. The dimensions of the X-ray detector entrance window are $300 \times 300$ $\mathrm{mm}$. X-ray detector pixel size $-140 \mu \mathrm{m}$. The minimum voxel size of the resulting image is generally $5 \mu \mathrm{m}$.

The dimensions of the X-ray protective chamber (lxwxh) are equal to $1100 \times 670 \times 550$ $\mathrm{mm}$, the dimensions of the research instrument chamber (chamber for placing the samples) allow examining objects up to $210 \times 250 \times 250 \mathrm{~mm}$ in size. The total weight of the tomograph does not exceed $250 \mathrm{~kg}$.

Examples of research results performed using the MRKT-04 tomograph are shown in Fig. 8.
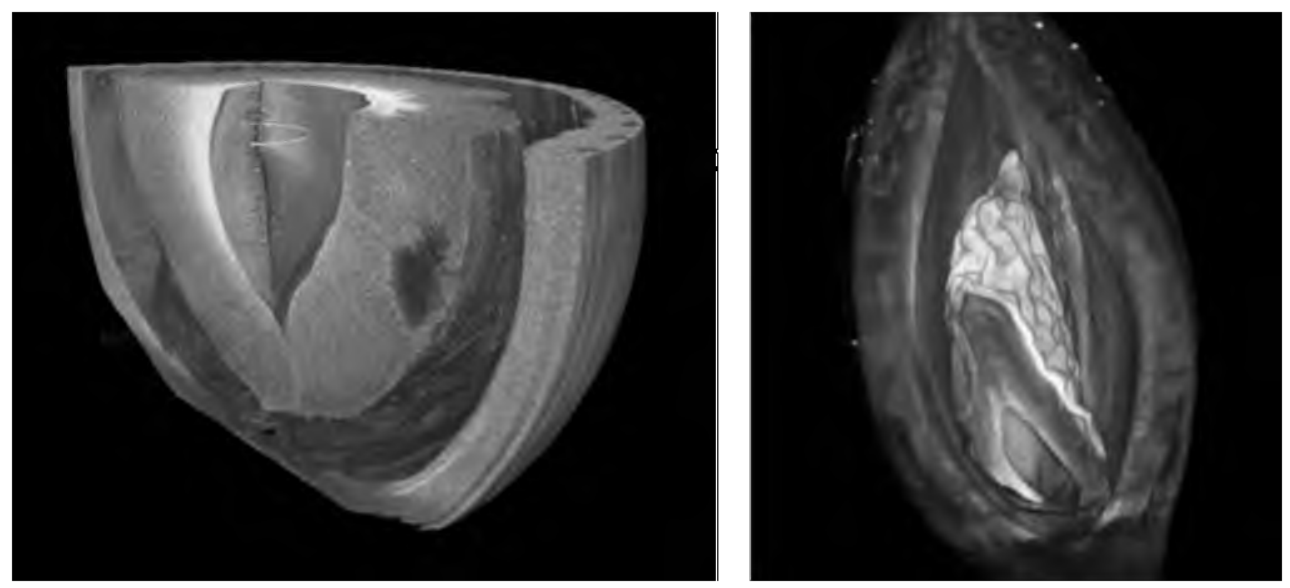

Fig. 8. Three-dimensional X-ray images - a) hazelnut (lat. nux pontica), b) plum (lat. prúnus).

\section{Conclusion}

The accumulated experience in the creation and operation of technical means for X-ray diffraction of seeds and plants allows asserting that in our country, a technology has been 
created and is being successfully developed for conducting such research in seed production and seed studies.

Both highly informative methods of carrying out X-ray of seeds and plants and the most modern technical means for their implementation have been developed. In the long term, full automation of the analysis of X-ray images and the creation of an appropriate regulatory framework in the form of the Russian State Standard GOST "Agricultural seeds. Methods of digital radiography" are planned.

\section{References}

1. Simak M 1970 New uses of $x$-ray method for the analysis of forest seed (Stockholm: IUFRO International of forest trees) pp 1-11

2. Simak M and Gustaffson A 1953 X-rays photography and sensibility in forest tree species J. Hereditas 39(4) 458-68

3. Kurbanov M R 1968 Seeds of wood species. X-ray analysis methods (Moscow: Goskomles USSR) p 22

4. Kurbanov MR 1984 Radiography of seeds with an enlarged image Bull. of the GBS of the USSR Academy of Sci. 133 97-101

5. Nekrasov V I and Smirnova N G 1971 Radiographic assessment of the quality of seeds. The quality of seeds in connection with the conditions of their formation during the introduction (Novosibirsk: Science) pp 60-9

6. Smirnova N G 1976 X-ray study of seeds of deciduous woody introduced plants (Moscow: Nauka) p 108

7. OST 56-94-88 1988 Seeds of tree species. Methods of X-ray analysis $\mathrm{p} 21$

8. Zaitsev V A, Redkina Z V and Grun L B 1981 Prospects for radiography in the diagnosis of seed quality J. Select. and seed prod. 7 37-8

9. Malevinsky V E, Zaitsev V A and Redkina Z V 1984 The influence of storage time on the germination energy of the germination of seeds of two-source reed Collection of scientific works of the Leningrad Agricultural Institute p 37

10. Zaitsev V A and Redkina Z V 1987 Possibilities and prospects of application of the method of X-ray analysis of agricultural seeds J. Elect. ind. Ser. 4 2(117) 117

11. Redkina Z V, Zaitsev VA and Arkhipov M V 1984 Radiography with direct X-ray magnification on the REIS-I emitter for the diagnosis of completion, injury and infection of seeds Bot. garden AN Lat. SSR ecological problems of seed research of introduced species: Abstracts (Riga) p 105

12. Ivanov S A and Shchukin G A 1989 X-ray tubes for technical purposes (Leningrad: Energoatomizdat Leningrad Department) p 200

13. Andrushchenko L G, Arkhipov M V, Grun L B, Ioffe Yu K, Redkina Z V and Fedorak N A 1983 Portable microfocus X-ray apparatus for diagnostics of seeds and grains $J$. Electr. Ind. 11(128) 31-34

14. Pechenova T V, Smirnova N G and Kholodova V K 1985 The use of radiography in the study of seed quality J. Sugar beet $1038-9$

15. Savin V N, Arkhipov M V and Badenko A L 1981 Radiography to identify internal injuries and their influence on the yielding qualities of seeds J. Agric. Sci. bull. 10(301) 99-104

16. Savin V N, Kondrashova M D and Arkhipov M V 1995 Influence of various types of damage to barley seeds on their sowing qualities and yielding properties Reports of the 
Russian Academy of Agricultural Sciences p 5-7

17. Savin V N, Arkhipov M V and Gusakova L P 1997 Viability of vegetable seeds in case of internal damage J. Agrar. sci. 2 23-25

18. Arkhipov M V, Alekseeva D I, Velikanov L P, Gusakova L P and Derunov I V 2005 Introscopic method for the accelerated determination of the latent population of grain by quarantine pests - Guidelines (St. Petersburg) p 24

19. Arkhipov M V, Gusakova L P and Alferova D V 2011Radiography of plants in solving problems of seed science and seed production J. Bull. of St. Petersburg Agr. Univ. 22 336-41

20. Arkhipov M V and Potrakhov N N 2008 Microfocus radiography of plants (St. Petersburg: Tekhnolit) p 192

21. Giants L P 1997 X-ray analysis of internal damage to wheat and barley seeds. Agrophysical methods and devices Plants and Their Habitat 3 (St. Petersburg: AFI) 234-54

22. Velikanov L P, Grundas S, Archipov M V, Demianichuk A M and Gusakova L P 2008 Agrophisical direction of further development and application of X-ray method Proc. of Int. Conf. on New Trends in Agrophysics (Lublin, Poland) pp 147-48

23. Blinov N N 2002 Fundamentals of X-ray Diagnostic Technique ed N N Blinova (Moscow: Medicine) p 392

24. Potrakhov N N, Gryaznov AYu, Lisenkov A A and Kostrin D K 2017 Past, present and future of the X-ray technique - a view from the 3rd international conference on X-ray technique $J$. of Physics $\mathbf{8 0 8 ( 1 )} 011001$

25. Grundas S, Velikanov L and Arkhipov V 1999 Importance of wheat grain orientation for the detection of internal mechanical damage by the X-ray method J. Int. Agrophysics 13 355-61

26. Narvankar D S, Singh C B, Jayas D S and White N D G 2009 Assessment of soft X-ray imaging for detection of fungal infection in wheat J. Biosyst. engineering 103(1) 49-56

27. Bruggink H and Duijn A van 2017 X-ray based seed analysis Seed Testing International ISTA News Bull. 153 45-50

28. França-Silva, Carvalho, Carvalho, Andrade, Souza and Marques 2019 Radiographic analysis to test maize seeds for the presence of Sitophilus Zea mais (Coleoptera: Curculionidae) J. Seed Sci. and Techn. 47(3) 249-60

29. Pinto T L F, Cicero S M, França-Neto J B and Forti V A 2009 An assessment of mechanical and stink bug damage in soybean seed using X-ray analysis test $J$. Seed Sci. and Techn. 37 110-20

30. Bino R J, Aartse J W and Van Der Burg W J 2009 Non destructive X-ray of Arabidopsis embryo mutants J. Seed Science Research 3(3) 167-70

31. Dell'Aquila A 2007 Pepper seed germination assessed by combined X-radiography and computer-aided imaging analysis J. Biologia Plantarum 51 777-81

32. Gagliardi B and Marcos-Filho J 2011 Relationship between germination and bell pepper seed structure assessed by the X-ray test J. Sci.Agric. 68(4) 411-16

33. Musaev F B, Potrakhov N Nand Arkhipov M V 2016 Radiography of vegetable seeds (St. Petersburg : Publishing house of StPg ETU "LETI") p 207

34. Musaev F B 2018 Scientific and practical aspects of improving the quality control of vegetable seeds Dissertation for the degree of Doctor of Agricultural Sciences (Odintsovo: Federal Scientific Center for Vegetable Growing) p 479 
35. Porsch F 2020 Automated seed testing by 3D X-ray computed tomography J. Seed Sci. and Techn. 48(1) 73-81

36. Potrakhov N N, Obodovsky A V, Bessonov V B, Potrakhov E N and Guk K K 2019 Xray tomography $J$. Photonics 13(7) 688-93

37. Bessonov V B, Larionov I A and Obodovsky A V 2019 Features of the development of software and hardware systems for microfocus X-ray computed tomography J. Phys. foundations of instrumentation 84(34) 23-33

38. Potrakhov N N, Beletskiy S L and Arkhipov M V 2018 Hardware and software complex for grain quality control based on mobile X-ray diagnostic unit PRDU-02 J.Tavr. Bull. of Agr. Sci. 4(16) 152-59

39. Musaev F B, Beletskiy S L and Potrakhov N N 2018 A brief atlas of radiographic signs of vegetable seeds (Moscow: Publishing house DeLi plus) p 52

40. Beletskiy S L, Musaev F B, Zheludkov A G, Antoshkina M S and Potrakhov N N 2018 The program for automatic control of the fulfillment of vegetable seeds "SortSemControl-1.0" Certificate of state registration of the computer program No. 2018616484 (RF) / copyright holder SPbGETU "LETI" (RU) Application No. 2018613760 date of receipt 04/16/2018 registration date 06/01/2018

41. Beletskiy S L, Zheludkov A G and Potrakhov N N 2019 A system for automated calculation of the basic quantitative characteristics of lots of seeds and grain obtained by the method of X-ray diffraction ("Passport-Grain") Certificate of registration of the computer program RU 2019618731, 04.07.2019 Application No 2019617593 dated June 252019 